\title{
Controlled ectomycorrhization of an exotic legume tree species Acacia holosericea affects root nodule bacteria diversity and their symbiotic effectiveness on Faidherbia albida, a native sahelian Acacia
}

Faye $A^{1,2}$, Krasova-Wade $\mathrm{T}^{2}$, Thiao $\mathrm{M}^{2,3}$, Thioulouse $\mathrm{J}^{4}$, Neyra $\mathrm{M}^{5}$, Prin $\mathrm{Y}^{6}$, Galiana $\mathrm{A}^{6}$, NDoye $\mathrm{I}^{2,3}$, Dreyfus $\mathrm{B}^{5} \&$ Duponnois $\mathrm{R}^{25 *}$

${ }^{1}$ ISRA. Laboratoire National de Recherches sur les Productions Végétales. Centre de Recherche de Bel Air. BP 1386. Dakar. Sénégal ; ${ }^{2}$ IRD. Laboratoire Commun de Microbiologie IRD/ISRA/UCAD. Centre de Recherche de Bel Air. BP; 1386. Dakar. Sénégal ; ${ }^{3} \mathrm{UCAD}$, Faculté des Sciences et Techniques, Département de biologie végétale, Dakar, Sénégal ; ${ }^{4}$ Laboratoire de Biométrie et Biologie Evolutive (UMR 5558); CNRS; Univ. Lyon 1, 43 bd 11 nov, 69622, Villeurbanne Cedex, France ; ${ }^{5}$ IRD. UMR 113 CIRAD/INRA/IRD/SUPAGRO/UM2. Laboratoire des Symbioses Tropicales et Méditerranéennes (LSTM). TA10/J, Campus International de Baillarguet. Montpellier. France ; ${ }^{6} \mathrm{CIRAD}$. UMR $113 \mathrm{CIRAD/INRA/IRD/SUP-AGRO/UM2.} \mathrm{Laboratoire} \mathrm{des} \mathrm{Symbioses} \mathrm{Tropicales} \mathrm{et}$ Méditerranéennes (LSTM). TA10/J, Campus International de Baillarguet, Montpellier, France

•E-mail: duponnoi@ird.sn

In the 400-700 mm rainfall zone, Acacia holosericea was found to be one of the best-adapted exotic tree showing excellent survival rate and rapid early growth (Harwood, 1994). In addition to rhizobial symbiosis, this tree species can form arbuscular mycorrhiza (AM) and/or ectomycorrhiza (De La Cruz \& Garcia. 1991, Founoune et al., 2002) and controlled mycorrhizal inoculation could improve its performance in glasshouse conditions (Duponnois et al., 2000a, 2001, 2003) đñd also after outplanting into the field (Duponnois et al., 2005, 2007). The impact of the establishment of exotic plant on the structure and function of native microbial communities was mainly unknown. Hence a study was conducted in a field experiment carried out in Senegal with A. holosericea, inoculated or not with an ectomycorrhizal strain Pisolithus albus IR 100 (Duponnois et al., 2005,2007 ) in order to evaluate the influence of this exotic fast growing leguminous tree on the native soil microbiota and the potential consequences on soil revegetalisation with native plant species. Among the targeted native species, the leguminous tree Faidherbia albida has been selected since it plays a major role in the agrosylvo-pastoral balance of the Sahelian regions of Africa. Our study shows that exotic plant species can drastically affect the genotypic and symbiotic effectiveness of native bradyrhizobia populations which could limit the natural regeneration of endemic plant species such as $F$. albida. But this field-base experimental research outlights the role of mycorrhizal symbiosis in afforestation programmes with exotic tree species that target preservation of native plants. 